\title{
Larval habitat associations with human land uses, roads, rivers, and land cover for Anopheles albimanus, $A$. pseudopunctipennis, and A. punctimacula (Diptera: Culicidae) in coastal and highland Ecuador
}

\section{Lauren L. Pinault* and Fiona F. Hunter}

Vector-Borne Diseases Laboratory, Department of Biological Sciences, Brock University, St. Catharines, ON, Canada

Edited by:

Rubén Bueno-Marí, University of

Valencia, Spain

\section{Reviewed by:}

Scott H. Harrison, North Carolina A\&T

State University, USA

Marco Scutari, University College

London, UK

\section{*Correspondence:}

Lauren L. Pinault, Vector-Borne

Diseases Laboratory, Department of

Biological Sciences, Brock University,

500 Glenridge Avenue, St. Catharines,

ON, Canada L2S 3A1.

e-mail: lauren.pinault@gmail.com

\begin{abstract}
Larval habitat for three highland Anopheles species: Anopheles albimanus Wiedemann, Anopheles pseudopunctipennis Theobald, and Anopheles punctimacula Dyar and Knab was related to human land uses, rivers, roads, and remotely sensed land cover classifications in the western Ecuadorian Andes. Of the five commonly observed human land uses, cattle pasture $(n=30)$ provided potentially suitable habitat for $A$. punctimacula and A. albimanus in less than $14 \%$ of sites, and was related in a principal components analysis (PCA) to the presence of macrophyte vegetation, greater surface area, clarity, and algae cover. Empty lots $(n=30)$ were related in the PCA to incident sunlight and provided potential habitat for A. pseudopunctipennis and A. albimanus in less than $14 \%$ of sites. The other land uses surveyed (banana, sugarcane, and mixed tree plantations; $n=28,21,25$, respectively) provided very little standing water that could potentially be used for larval habitat. River edges and eddies $(n=41)$ were associated with greater clarity, depth, temperature, and algae cover, which provide potentially suitable habitat for $A$. albimanus in $58 \%$ of sites and A. pseudopunctipennis in $29 \%$ of sites. Road-associated water bodies $(n=38)$ provided potential habitat for $A$. punctimacula in $44 \%$ of sites and $A$. albimanus in $26 \%$ of sites surveyed. Species collection localities were compared to land cover classifications using Geographic Information Systems software. All three mosquito species were associated more often with the category "closed/open broadleaved evergreen and/or semi-deciduous forests" than expected ( $P \leq 0.01$ in all cases), given such a habitat's abundance. This study provides evidence that specific human land uses create habitat for potential malaria vectors in highland regions of the Andes.
\end{abstract}

Keywords: Ecuador, Anopheles, land use, land cover, highland malaria

\section{INTRODUCTION}

Recent studies have identified the presence of multiple Anopheles species as well as the occasional small-scale epidemic of malaria in the highlands of the northern and central Andes (Rutar et al., 2004; Pinault and Hunter, 2011a). Although land use and land cover are strongly associated with Anopheles larval habitat, increasing populations of the vectors, and malaria incidence in the highlands of Africa (e.g., Brinkmann, 1994; Shanks et al., 2000; Hay et al., 2002; Afrane et al., 2005), the associations of the highland-occurring Anopheles species in the Andes with land uses have been hitherto unknown.

Conversion of a property to a specific land use may alter the presence and abundance of local Anopheles species by creating potentially suitable larval habitats (reviewed in Reiter, 2001; Chhabra et al., 2006). Certain land uses are frequently associated with anopheline larval habitat on different continents, including rice farms (Brinkmann, 1994; Reiter, 2001), fish farms, particularly abandoned fish ponds (Reiter, 2001), as well as cattle pastures where cattle footprints create permanent depressions that fill with rainwater (Reiter, 2001).
In addition to creating potential larval habitat, reduced canopy cover in the highlands (in disturbed or deforested habitats) may influence anopheline habitat suitability by altering the local microclimate (Patz et al., 2004; Minakawa et al., 2005; Chhabra et al., 2006; Guerra et al., 2006; Pattanayak et al., 2006; Yasuoka and Levins, 2007). Deforested areas are approximately $0.5^{\circ} \mathrm{C}$ warmer than adjacent forested regions in highland Kenya (Afrane et al., 2005, 2006). Anopheles gambiae Giles in highland Kenya have $64.8-79.5 \%$ higher fecundity rates, a $40 \%$ higher net reproductive rate and a $29 \%$ higher vector capacity (Afrane et al., 2006), as well as a shortened gonotrophic cycle in deforested rather than forested regions (Afrane et al., 2005). Increasing temperatures have been shown to have non-linear, positive effects on anopheline larval development rates (Paaijmans et al., 2010). In South America, deforestation has also been associated with malaria incidences, particularly for road building, gold mining, or permanent colonization or urbanization, most prominently in parts of the Amazon (Pinheiro et al., 1977; Walsh et al., 1993; Tadei et al., 1998; Póvoa et al., 2003; Caldas de Castro et al., 2006; Guerra et al., 2006; Yomiko Vittor et al., 2006; Pan et al., 2010; de Oliveira et al., 2011). 
In malaria-endemic highland regions of Africa, anopheline larval habitat is limited by steep topography to areas where water accumulates (e.g., Balls et al., 2004), often in valley bottoms (Munga et al., 2009). In the Usambara mountains of Tanzania, Anopheles larvae live in sunlit pools that offer a warmer microclimate, and may be associated with the irrigated vegetable-growing terraces (Bødker et al., 2000). A. gambiae are associated with open habitat in farmlands and pastures in highland Kenya, particularly in water-collecting valley bottoms (Munga et al., 2009).

In South America, where highland malaria is less well-studied, Andean highland valleys were afflicted with cases of highland malaria during the 1940s, vectored by A. pseudopunctipennis (Levi Castillo, 1945). However, Levi Castillo (1945) documented the removal of this vector from highland valleys near Quito, Ecuador through the elimination of larval habitat and the use of chemical insecticides. Since that time, highland areas have been generally considered malaria-free (Pinault and Hunter, 2011a).

Land use changes in the Ecuadorian Inter-Andean valleys, particularly the conversion of highland páramo and forests to crops and pasture, occurred over vast areas during pre-Colombian times (Sarmiento, 2002). However, widespread land use changes have occurred in Ecuador during the last century in the coastal and Amazonian regions. The humid tropical forests of the coast were colonized during the cocoa boom in the 1920s and the banana boom in the 1950s, during which an extensive road network was built linking ports to inland coastal cities and highland Andean cities (Wood, 1972; Bromley, 1981). This road building led to informal colonization of foothill regions (ca. 500-1500 m) to grow sugarcane and oranges (Wood, 1972; Bromley, 1981). The northern Amazon was heavily colonized during the oil boom in the 1970s, when large-scale road networks were built to accommodate the oil industry (Wood, 1972; Bromley, 1981). Settler colonies built slash and mulch polycultures to farm rice, yams, corn, plantain, and yucca, that were later converted to pasture (Hiraoka and Yamamoto, 1980).

More recent studies of land use in Ecuador indicate the presence of permanent crops at lower elevations of the Andes, with denser human populations associated with temporary crops. Grasslands for pasture are associated with fertile soil, whereas economically poor areas are often associated with natural vegetation (no human land use; de Koning et al., 1998). On the coast, permanent export crops with widespread irrigation are favored, whereas in the Amazon, there is a trend for agricultural colonists to convert forest to grassland to be used as pasture (de Koning et al., 1998).

In this study, we evaluate the hypothesis that land use change is responsible for the proliferation of multiple vector species in the western highlands of Ecuador by creating suitable larval habitat. We predict that current land uses would provide potentially suitable habitat for larvae of three species of western-occurring malaria vectors. In this study, we relate the most common land uses, as well as the presence of rivers and roads on the western cordillera of the Andes, to potentially suitable larval habitat for Anopheles albimanus, Anopheles pseudopunctipennis, and Anopheles punctimacula. We also compare the distribution of these species based on recent collections to published land cover classification maps. The purpose of this study was to identify human land uses and land covers that provide potentially suitable larval habitat for each of the three common Anopheles species, as well as to relate any of these species to the presence of roads and rivers that may serve as lowland-highland corridors, and thereby identify priority larval habitat types. Although the incidence of malaria has declined substantially in Ecuador in recent years due to government intervention, malaria persists at low levels in certain coastal and Amazonian regions (SNEM, 1995-2009), therefore, studies of vector ecology are still pertinent.

\section{MATERIALS AND METHODS LAND USE}

In the present study, we attempt to characterize anopheline larval habitat availability in the highlands, i.e., steep topography areas of the western Andes of Ecuador. These lie conservatively from 500 to $2000 \mathrm{~m}$ in elevation, the latter being the current maximum altitudinal limit for collections of the three more common species (Pinault and Hunter, 2011a). To determine potential habitats made available by highland land uses, it was first necessary to characterize the most common land uses present between 500 and $2000 \mathrm{~m}$. To that end, researchers surveyed land uses present along six altitudinal transects in the western Andes in 2009 and 2010, along the east-west roads from: Quito to La Independencia (ca. N01 $02^{\prime}$ ), Pilaló to Quevedo (ca. S00 $53^{\prime}$ ), Guaranda to Puebloviejo (ca. S0 $1^{\circ} 35^{\prime}$ ), Chimbo to Babahoyo (ca. S0 $1^{\circ} 45^{\prime}$ ), Alausí to El Triunfo (ca. S02 ${ }^{\circ} 18^{\prime}$ ), and Loja to Machala (ca. S03 ${ }^{\circ} 52^{\prime}$ ). Researchers progressed very slowly along the roadway in a motor vehicle and stopped at $100 \mathrm{~m}$ elevation intervals to record the dominant land use, vegetation type, presence of water bodies, and geographical coordinates and altitude (using a Garmin ${ }^{\circledR}$ GPS eTrex Summit) observed on the right-hand side of the roadway (along the downhill trip). The six most commonly observed land uses were ascertained graphically and used in subsequent analyses.

To determine the potential anopheline larval habitat made available on the most common land uses within the highlands (determined above), researchers traveled along accessible roads in the western Ecuadorian Andes in summer, fall, and winter during 2009 and 2010 and searched for the following land uses: cattle farms, banana plantations, mixed tree plantations (including citrus fruits), sugarcane plantations, and empty lots/cleared land. To randomly select half of the available sites, at each potential site researchers flipped a coin to determine if the property would be sampled, then, permission was sought from the landowner or manager to enter the property for the purpose of the survey (except empty lots/cleared land, which were most often public domain). Between 21 and 30 sites were sampled for each land use type.

At each site, researchers recorded the geographic coordinates and altitude using a GPS as above, and the air temperature. Researchers then moved about the property and observed every potential anopheline habitat (i.e., standing water or slow-moving water bodies), recording the length, width, and depth, water temperature (Hanna Instruments HI98129 combination water tester), percentage cover of algae and macrophyte vegetation $(10 \%$ classes), incident sunlight ( $10 \%$ classes), and water clarity $(10 \%$ classes). In every water body, water was dip-sampled using a white plastic dipper (BioQuip) for Anopheles larvae a standard of 30 times (although five dips were used for very small water 
bodies). When larvae were collected, these were placed in vials containing 95\% ethanol, transported to the laboratory, and identified to species using the morphological key of Gorham et al. (1973) and molecular techniques as in Pinault and Hunter (2011a). Specimens not destroyed for molecular sequencing were deposited in the Ecuadorian National Collection in Quito (PUCE) and nucleotide sequences were deposited in GenBank (accession numbers JN412826-JN412843) When property sizes were greater than five hectares, researchers sub-sampled a portion of the property (approximately two hectares in size).

For sites with water bodies, an average value of the parameters above was obtained for each site and entered into a principal components analysis (PCA) to determine its relation to land use type (entered individually with dummy variables; CANOCO, 2002). Data were standardized by conversion of values to $Z$-scores using the mean and SD of the data set to ensure that factors were similarly weighted, and centered around zero prior to analysis (Whitlock and Schluter, 2009). Water bodies were then judged for potential suitability for A. albimanus, A. pseudopunctipennis, and A. punctimacula larvae using the following criteria, derived from field-based observations made during work conducted in Pinault and Hunter (2012). We therefore chose limiting temperatures and other criteria that would include all observed values from field sites. A. albimanus-suitable habitats were permanent water bodies with some floating algae (at least $10 \%$ cover) and within a temperature range of $22-33^{\circ} \mathrm{C}$. A. pseudopunctipennis-suitable habitat contained some floating algae (at least $10 \%$ cover), $40 \%$ clarity or greater, less than $10 \%$ cover of emergent vegetation, and temperatures within the range of $20.3-37.0^{\circ} \mathrm{C}$. A punctimacula-suitable habitats were water bodies with less than $70 \%$ incident sunlight and less than $50 \%$ algae cover, with temperatures in the range of 19.5-28. $6^{\circ} \mathrm{C}$. All criteria represent values that are conservative, i.e., are more likely to include a site as potentially suitable for larvae than not, since there is some natural variation in larval habitat site suitability.

\section{RIVER AND ROAD EDGES}

Water bodies associated with rivers and roads were assessed as potential anopheline larval habitats in highland regions. Since roads and rivers form continuous rather than discrete sample areas, the site-selection process for sites was different than for land uses. Researchers searched in the western Andes for river and road sites that had at least one stagnant or slow-moving body of water that may have been potentially suitable for anopheline larvae, and flipped a coin to determine if the site would be used or not. At each site, all water bodies were scrutinized using the same criteria and sampled for anopheline larvae as above (for land uses) within a $10 \mathrm{~m}$ circular study radius. A total of 41 river sites and 38 road edge sites were surveyed. Data were analyzed using a PCA and assessed for potential species suitability as described above.

To determine the spatial distribution of road edge habitats, researchers undertook three altitudinal transects along the following roads: Ibarra to Lita (ca. N00 $50^{\prime}$ ), Quito to Puerto Quito (ca. $\mathrm{N} 00^{\circ} 06^{\prime}$ ), and Alausí to El Triunfo (ca. S02 ${ }^{\circ} 18^{\prime}$ ). We were restricted to these roads due to safety issues regarding conducting research in traffic-heavy sections of other roads. Researchers traveled slowly along the road and stopped at every stagnant or slow-moving water body observed on the right side of the road. Water type, size, coordinates, and altitude were recorded as above. To determine the degree of clustering of water bodies along each road, water bodies were plotted in ArcGIS v. 9.2 (ESRI, 2008) and analyzed using the Spatial Autocorrelation (Moran's I index) tool, weighted by total water surface area. Moran's I (MI) determines whether spatial data is clustered, dispersed, or randomly distributed (Moran, 1950).

\section{LAND COVER}

Land use can affect larval habitat availability through changes to the vegetation architecture and degree of canopy openness. For this reason, we determined the land cover for each of the positive collection localities from Pinault and Hunter (2011a) for each of the three Anopheles species above. Collection sites were plotted in Arc GIS v. 9.2 with the GlobCover ${ }^{\odot} 2009$ land cover map, published by the European Space Agency and the Université Catholique de Louvain. The GlobCover ${ }^{\odot}$ data presents mosaics of the 22 land cover classes of the United Nations Land Cover Classification System at $300 \mathrm{~m}$ resolution, derived from a time series of global MERIS (MEdium Resolution Imaging Spectrometer; Bontemps et al., 2011; available at ArcGIS online, 2011). Land use values on raster tiles corresponding to distribution (collection) points were enumerated and compared to expected values derived from the availability in the overall landscape, using a Chi-square test.

\section{RESULTS \\ LAND USE}

Land uses on total of 263 sites were recorded along five altitudinal transects. Of these, 117 sites were observed to be "natural," i.e., were not used for any discernable purpose and were not recently disturbed in any way, with an average altitude of $1705 \pm 654 \mathrm{~m}($ mean $+\mathrm{SD})$. Of natural sites, 47 of these were too steep to be used by humans (i.e., cliffs), with an average altitude $1617 \pm 313 \mathrm{~m}$. Human-use sites observed along the transects are plotted in Figure 1. Within the elevations of interest (500-2000 m), the most common land uses observed are: cattle pastures (51 sites), human habitations (13 sites), banana plantations ( 9 sites), sugarcane plantations ( 8 sites), mixed tree plantations, including citrus fruit species (6 sites), and cleared land/empty lot/construction sites (4 sites; Figure 1). In a concurrent study, human habitations provided almost no standing water other than cement laundry tanks, rain barrels, and septic tanks, all of which are unsuitable for anopheline larvae (Pinault and Hunter, 2011b). Therefore, the remaining five land uses were used in the subsequent land use survey.

In the survey of properties of pre-established land uses, the largest of the five property types were cattle pastures $(n=30$; area $36117 \pm 77351 \mathrm{~m}^{2}$ ), with an elevation of $1435 \pm 517 \mathrm{~m}$, then banana plantations $\left(n=28\right.$; area $\left.13215 \pm 32835 \mathrm{~m}^{2}\right)$, with an elevation of $887 \pm 534 \mathrm{~m}$, sugarcane plantations $(n=21$; area $\left.6870 \pm 8682 \mathrm{~m}^{2}\right)$, with an elevation of $1249 \pm 437 \mathrm{~m}$, mixed tree plantations $\left(n=25\right.$; area $\left.6012 \pm 6198 \mathrm{~m}^{2}\right)$, with an elevation of $795 \pm 502 \mathrm{~m}$ and finally empty lots $\left(n=30\right.$; area $\left.2335 \pm 2504 \mathrm{~m}^{2}\right)$ with an elevation of $1294 \pm 557 \mathrm{~m}$. The five human land uses were related to water body characteristics measured at each 
water-present site using a PCA (Figure 2). In the first bi-plot, banana plantations and mixed tree plantations are strongly related on Axis 1 to depth and negatively related to incident sunlight, while empty lots are strongly associated with incident sunlight (Figure 2A). On Axis 2, cattle pasture is strongly related to macrophyte vegetation, increasing surface area, clarity, and algae cover (Figure 2A). In the second bi-plot, banana plantations and empty lots are associated with incident sunlight and to a lesser extent, depth, and higher temperature on Axis 1 (Figure 2B). On Axis 3,

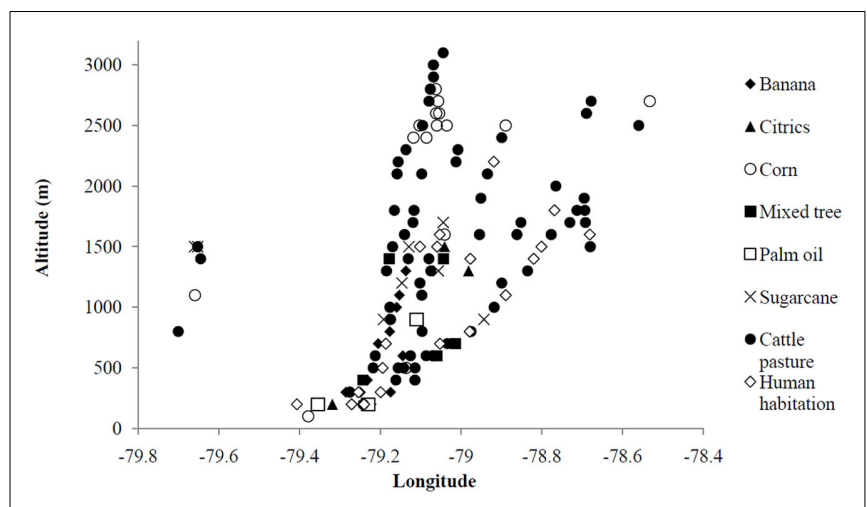

FIGURE 1 | Generalized land uses observed along six altitudinal transect in the western Ecuadorian Andes, plotted by longitude.

Elevations of biological interest are indicated within a black rectangle and land use types are indicated by symbols (see legend). cattle farms are associated with macrophyte vegetation and algae cover, as well as with altitude, and surface area (Figure 2B). A total of $54.7 \%$ of the cumulative variance was explained by the first three Axes, with the following Eigenvalues: Axis 1: 0.215, Axis 2: 0.183 , Axis 3: 0.149 .

All sites with standing water were analyzed for potential habitat suitability for the three anopheline species, and plotted in Figure 3A. The human land use type with the most sites with available standing water were empty lots $(40 \%$ of sites with some type of standing water), $13.3 \%$ of which were potentially suitable for A. pseudopunctipennis and $10 \%$ potentially suitable for $A$. albimanus (Figure 3A). In second place, 33.3\% of cattle pastures had some type of standing water, $13.3 \%$ potentially suitable for A. punctimacula, and $10 \%$ potentially suitable for A. albimanus (Figure 3A). A. albimanus larvae were collected from one empty lot site (9 larvae) and one cattle pasture site (93 larvae). The other land uses in highland regions were quite dry, with $16 \%$ of mixed tree plantations, $14.3 \%$ of sugarcane, and $7.1 \%$ of banana farms containing any standing water, most of which was unsuitable for anopheline larvae (Figure 3A). Anopheles larvae were not collected at any other sites.

\section{RIVER AND ROAD EDGES}

Road and river sites were sampled at mean elevations of $1411 \pm 407$ and $1034 \pm 537 \mathrm{~m}$, respectively. Figure 4 presents the bi-plot results of a PCA relating roads and rivers to water body characteristics. In the first bi-plot, rivers are associated with clarity and to a lesser degree, depth, whereas roads are weakly associated with
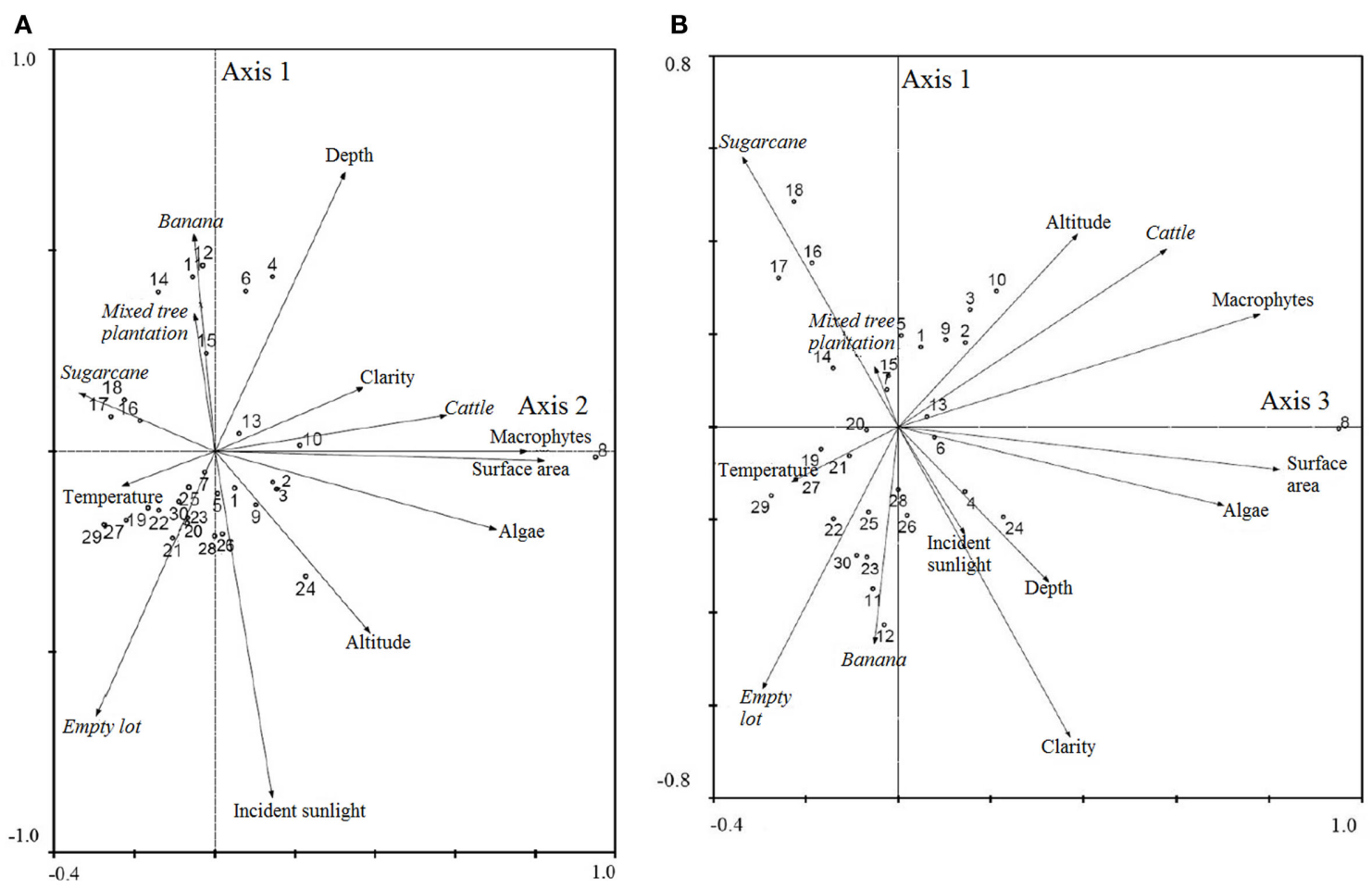

FIGURE 2 | Bi-plot results of principal components analysis of land uses and habitat characteristics for (A) Axes 1 and 2 and (B) Axes 1 and 3. Output from CANOCO (2002). 
macrophyte vegetation cover along Axis 2 (Figure 4A). The water body characteristics of temperature, incident sunlight, and algae were inversely related to altitude (Figure 4A). In the second bi-plot, rivers and roads are separated along Axis 3 (Figure 4B). Rivers are weakly associated with temperature, depth, algae cover, clarity, and incident sunlight, whereas roads are related to increasing altitude (Figure 4B). The number of active samples in the PCA were 79, and a total of $57.2 \%$ of the cumulative variance was explained by the first three Axes, with the following Eigenvalues: Axis 1: 0.296, Axis 2: 0.160, Axis 3: 0.116.

Roads and rivers were judged to have a high proportion of sites that would be potentially suitable for anopheline larvae. Roads were judged to provide the most potential habitat for A. punctimacula (44.7\%), followed by A. albimanus (26.3\%; Figure 3B). Rivers, on other hand, provided the most potentially suitable habitat for A. albimanus (58\%), followed by A. pseudopunctipennis (29.3\%; Figure 3B). In terms of actual collections of anopheline larvae, one road site was positive for A. albimanus larvae (three larvae), three sites were positive for A. punctimacula larvae $(4.3 \pm 1.2$ larvae; mean $\pm \mathrm{SD}$ ), and one site was positive for $A$. pseudopunctipennis larvae (6 larvae). Rivers provided the most current Anopheles habitat, with a total of 19 larval-present sites: $12 \mathrm{~A}$. pseudopunctipennis sites (41.2 \pm 56.8 larvae), five A. punctimacula sites (29.0 \pm 34.4 larvae), and two A. albimanus sites $(34.5 \pm 38.9$ larvae).

Of the three roadside water transects, Ibarra to Lita provided 21 water-present sites, followed by 15 sites for Quito to Puerto Quito and 6 sites for Alausi to El Triunfo. Most water bodies were roadside ditches, but permanent tire tracks, inland ditches, and pools formed by construction activities were also associated with roads. Spatial Autocorrelation analysis indicated that all three transects were significantly randomly distributed, rather than clustered at specific elevations (Ibarra-Lita transect: $\mathrm{MI}=0.21, Z=-0.57$; Quito-Santo Domingo transect: $\mathrm{MI}=-0.02, Z=-0.08$; Alausi-El Triunfo transect: $\mathrm{MI}=-0.22, Z=-0.04)$. Anopheles larvae were only collected at four sites, with $A$. pseudopunctipennis larvae collected at two sites of ca. $1500 \mathrm{~m}$, and A. albimanus larvae collected at two sites of ca. $600 \mathrm{~m}$ in elevation.

\section{LAND COVER}

Collection localities for the three species were related in ArcGIS to the U.N. land cover classification system. All three species were the mostly strongly related to the classification "closed/open broadleaved evergreen and/or semi-deciduous forest" (Figure 5), significantly more often than expected given its availability in the landscape $\left(A\right.$. albimanus: $\chi^{2}=18.70, \mathrm{df}=2, P<0.01 ; A$. pseudopunctipennis: $\chi^{2}=8.88, \mathrm{df}=2, P=0.01$; A. punctimacula: $\left.\chi^{2}=19.33, \mathrm{df}=2, P<0.01\right)$. A. albimanus were also often associated with "mosaic cropland (50-70\%)/vegetation," while $A$. pseudopunctipennis was less specifically associated with one land cover type; rather, it was broadly associated with several land cover classifications (Figure 5). A. punctimacula was more specific and collected from fewer land cover types (Figure 5).

\section{DISCUSSION}

Our study has identified land uses (including rivers) that may be more amenable to the development of anopheline larvae in

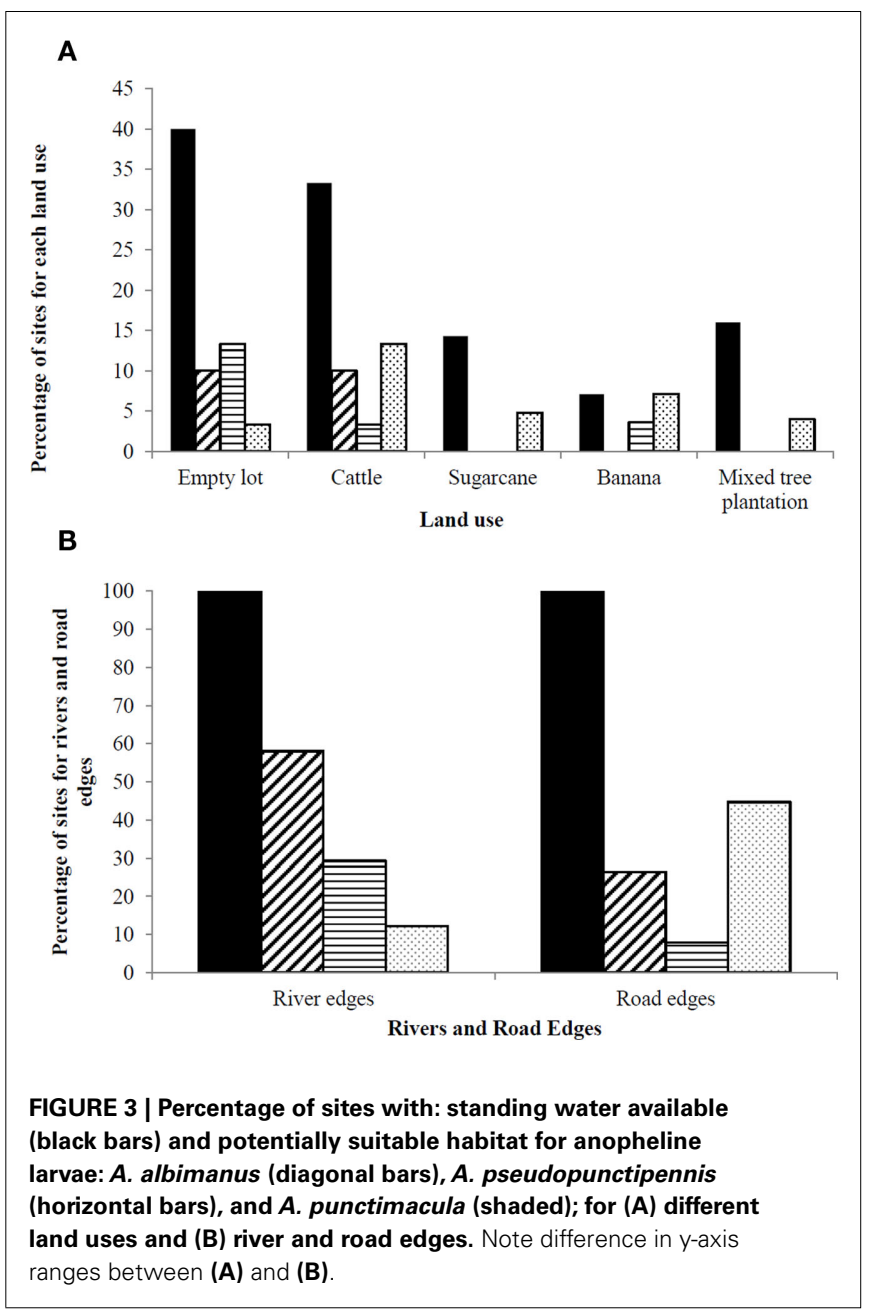

the western highlands of Ecuador. Cattle pasture can be considered the managed traditional land use most of concern. Cattle pasture was the land use most commonly observed during the transects (i.e., it is abundant), as well as having the largest property size of all the land uses examined, with an average area of $36617 \mathrm{~m}^{2}$. Thirty-three percent of cattle pastures surveyed contained standing water, with less than $13.3 \%$ potentially suitable for each of the anopheline species. Although the water bodies on cattle pasture were associated in the PCA with higher water clarity, which is favorable for all three species, and algal cover, which is very favorable for A. albimanus and A. pseudopunctipennis, water bodies were also associated with macrophyte vegetation cover, which is unsuitable for all three species (Pinault and Hunter, 2012). Given the extent of cattle pasture in the highlands of Ecuador, priority ought to be given to ponds and other "natural" water bodies used to provide cattle with drinking water. The use of drainable troughs, including the frequently used halftire troughs, may be recommended to cattle farmers to eliminate potentially suitable pooling of water. Similarly, flooded parts of pasture are of concern as well; in Mexico, A. albimanus are associated with regions of flooded cattle pasture (Rejmankova et al., 1991). 


\section{A}

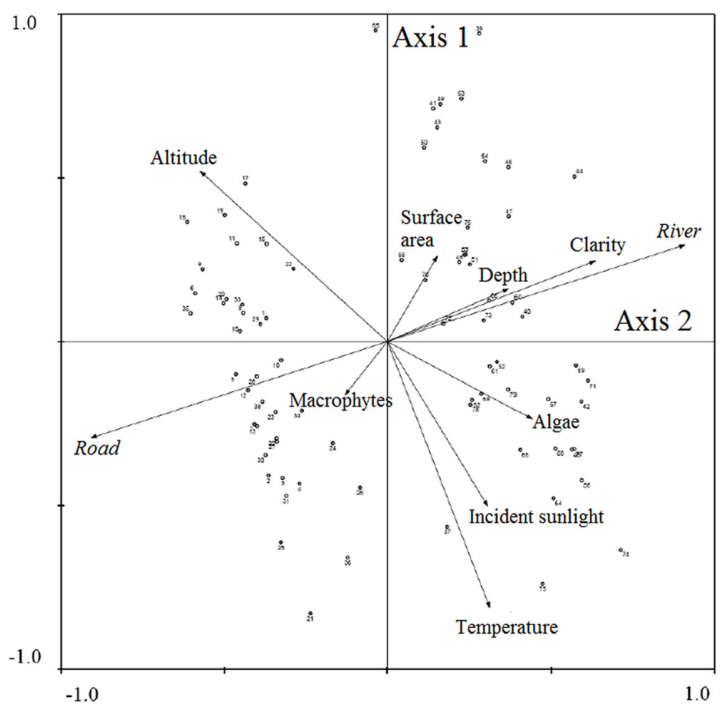

B

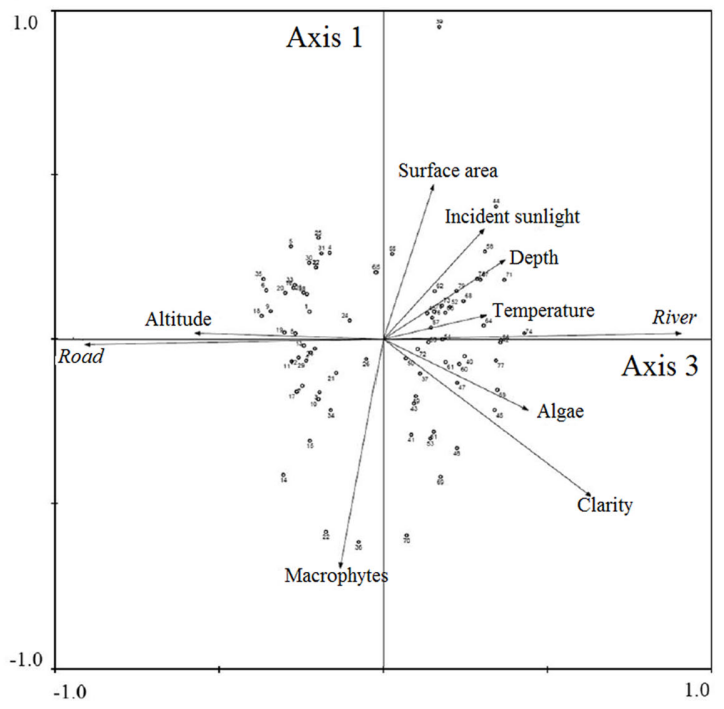

FIGURE 4 | Bi-plot results of principal components analysis of rivers/roads and habitat characteristics for (A) Axes 1 and 2 and (B) Axes 1 and 3. Output from CANOCO (2002).

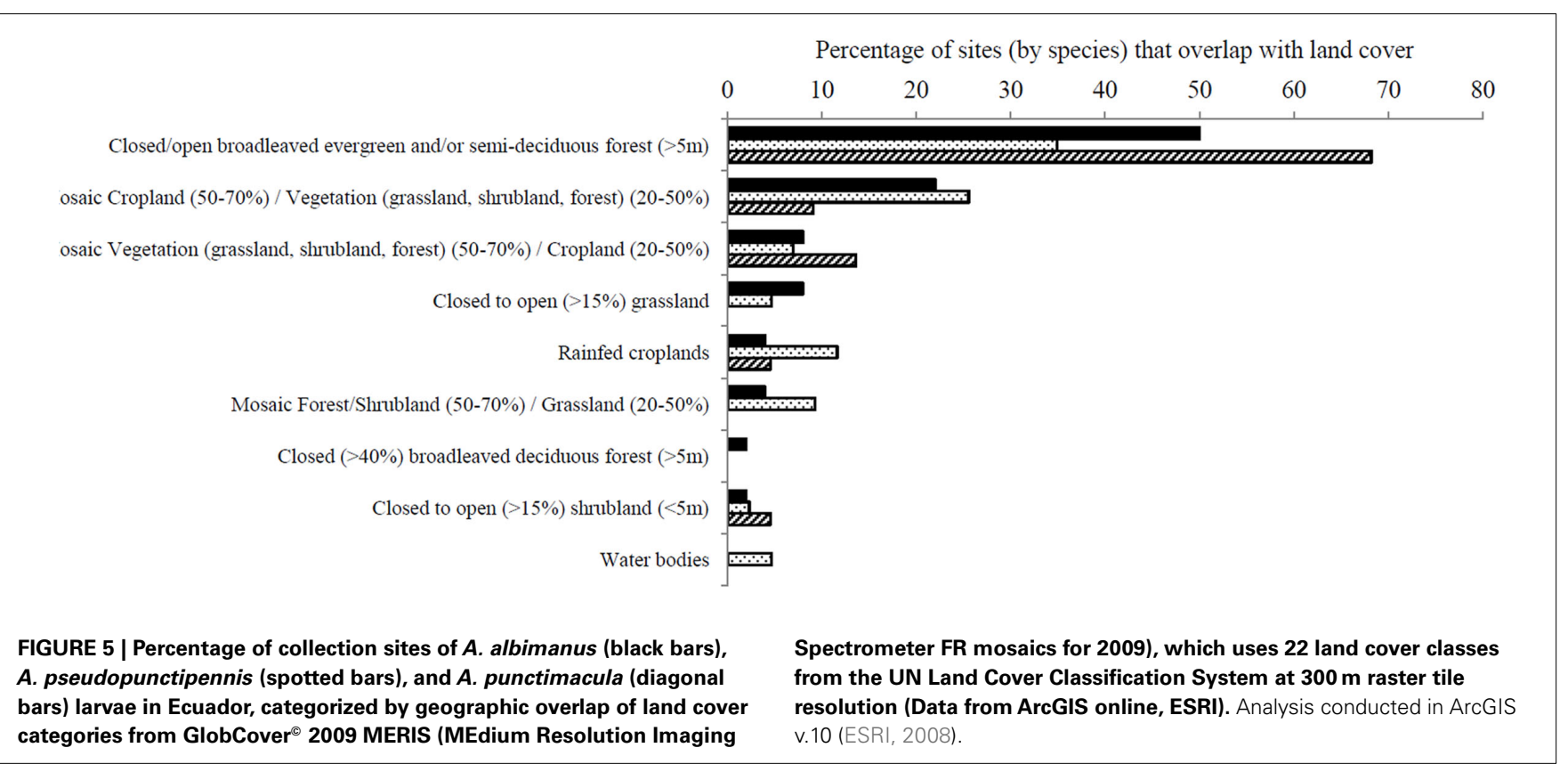

Although more standing water was observed on empty lots, these were the least-observed land use in the altitudinal transects and the smallest in size. Incident sunlight is high, favoring A. albimanus and A. pseudopunctipennis larvae, where water bodies exist. Most often, construction activities and heavy machinery tear apart the surface of the earth, creating permanent depressions, including permanent tire tracks, that fill with water. Better management of these sites for mosquito habitat elimination would involve ensuring that the ground is carefully leveled prior to its temporary or permanent abandonment by a construction company.
Unlike on the coast, banana, sugarcane, and mixed tree plantations are generally dry in highland (steep) regions and do not provide much, if any, potentially suitable standing water for Anopheles larvae. Therefore, none of these common land uses ought to be considered priority areas for standing water elimination or malaria prevention in the highlands of Ecuador. In Belize, the runoff from sugarcane plantations can lead to a bloom of Typha domingensis Personnel., which is negatively correlated to the presence of A. albimanus larvae (Grieco et al., 2006), and may exclude larvae from sugarcane-adjacent water bodies in Ecuador as well. 
Roads were associated in the PCA with macrophyte vegetation cover, which is a less suitable characteristic for Anopheles larval habitat. Although, roads often provide sunlit, open habitat, which were judged in $44 \%$ of cases to be potentially suitable for A. punctimacula and $26 \%$ of cases for A. albimanus, A. albimanus, and $A$. pseudopunctipennis were actually collected in two clusters of sites during roadside transects. Five out of the 38 sites sampled provided larvae during sampling, and densities of larvae collected in roadsides were similar to those observed during other collection efforts (Pinault and Hunter, 2011a). Despite the apparent clustering pattern, water bodies were not clustered at specific altitudes with less severe slopes, but rather, randomly distributed along roadways. Cement ditches placed along the roadways often became clogged with debris from adjacent trees and rocks, and subsequently filled with water permanently. Although road workers do periodically remove this debris, this study documents the use of these water bodies by anopheline larvae, necessitating more vigilance, and ensuring that roadside ditches along highways are frequently drained, especially at lower elevations.

River-associated habitat appeared to be important to anopheline larvae in the western highlands of Ecuador. Rivers were associated with greater water clarity, higher temperatures, the presence of algae, and incident sunlight, all of which are very suitable characteristics for A. albimanus and A. pseudopunctipennis. Although $58 \%$ of sites were judged suitable for $A$. albimanus and $29 \%$ for A. pseudopunctipennis, A. albimanus were collected more often in low-altitude river systems, while $A$. pseudopunctipennis were abundant in highland rivers that feed from most higher-altitude watersheds. A. punctimacula frequently co-occurs in the same river alongside A. pseudopunctipennis, although the two were never found to cohabit the same water bodies. Nineteen of the 41 sites sampled had larvae present, and larval abundance in these water bodies was similar in density to those from previous sampling efforts (Pinault and Hunter, 2011a). The presence of Anopheles larvae in highland rivers was observed historically in Balzapamba $(650 \mathrm{~m})$, where A. pseudopunctipennis larvae were collected in river-associated pools formed by an earthquake and subsequent landslide (Hanson and Montalvan, 1938). Similarly, Levi Castillo (1947) documents A. pseudopunctipennis in highland river edges in the late 1940s.

If rivers produce a large proportion of suitable habitat, they may provide corridors for the passage of anopheline mosquitoes to move into higher-altitude regions with favorable meteorological conditions. Although rivers are not technically a human land use, rivers in Ecuador are modified by adjacent land uses that sometimes includes the dumping of rocks and boulders into the stream, the construction of off-shoot canals for irrigation and drainage (that are not well-maintained) and the presence of water-collecting tubes that force water to collect in pools and slow-moving streams on the edges of rivers. Another possible source of larval habitat is the reduction of river flow due to either the diminished glacierfed streams from glacier disappearance due to climate change (Bradley et al., 2006; Vergara et al., 2007) or to the modification of the river flow due to the construction of hydroelectrical dams (Vergara et al., 2007; L. Pinault, personal observation). When the flow is sufficiently reduced, a greater surface area is available on the river edge within the original streambed for the formation of rock pools and slow-moving water streams. It is therefore the author's recommendation that highland rivers and streams (ca. 1500-2500 m) be monitored for the presence of Anopheles larvae in the western Andes to forecast and prevent future highland malaria incidences. As well, construction and hydrological projects that reduce river flow ought to ensure that the river edge walls are sufficiently steep, or that boulders and other impediments are removed from the river, to prevent the formation of water pools and slow-moving offshoots on the edges of rivers.

Since land use including roads and rivers is a strong driver of highland malaria, several authors have stressed the importance of relating specific land use changes to the distribution of infectious disease to predict and control future incidences and epidemics (e.g., Patz et al., 2004; Munga et al., 2009). For example, in Nigeria, water bodies related to specific types of farming such as trenches, dams, and irrigation have been identified as potential anopheline larval habitat (Oladepo et al., 2010). Farmers in these regions have been provided with these data, resulting in many farmers now managing their property to prevent the formation of standing water (Oladepo et al., 2010). The identification of cattle farms, river edges, and road edges as potential sources of anopheline larval habitat in highland regions of Ecuador implies that managers of these land use types ought to be targeted in source reduction educational programs.

In the management of highland anopheline species, insecticide spray programs used with larval habitat management have been demonstrated to be particularly effective due to the limited number of habitats available (e.g., de Zulueta et al., 1964). The identification of specific highland habitats associated with land uses, such as permanent cattle watering holes/ponds and modified rivers, allows malaria prevention programs to target these habitats in highlands and thereby reduce populations of potential malaria-vectoring mosquitoes. Finally, regional mapping of highland larval habitats based on our findings may allow community members and malaria control personnel to either eliminate habitat or initiate spray programs when required.

\section{ACKNOWLEDGMENTS}

The authors thank E. Santiago Caizapanta and Julio Rivera for field assistance in Ecuador, Aynsley Thielman, Alina Cywinska, and Jess Vickruck for laboratory assistance, Clifford Keil (PUCE), Renato León (USFQ) for laboratory collaboration in Ecuador, Liette Vasseur for assistance with CANOCO and multivariate statistics, as well as Glenn Tattersall, John Middleton, and two reviewers at the IDRC for helpful comments during the planning phase of the study. This research operated under the following permits from the government of Ecuador: No017-08 IC-FAU-DNBAPVS/MA; N00026/DRF-GLR-EO-SE-B-MA; N02-2009-IC-FAU-DPAC/MA; No03 RMDPM-MA; N¹6-2009-IC-FAU-DPAP/MA; Nº16-IC-FAU/FLODPN/MA; $\mathrm{N}^{\circ} 031$-FAU-DPE-MA, as well as appropriate export permits, as required. Finally, this study was funded by an NSERC Discovery Grant to Fiona F. Hunter, an IDRC doctoral research award to Lauren L. Pinault and an NSERC PGS to Lauren L. Pinault. 


\section{REFERENCES}

Afrane, Y. A., Lawson, B. W., Githeko, A. K., and Yan, G. (2005). Effects of microclimatic changes caused by land use and land cover on duration of gonotrophic cycles of Anopheles gambiae (Diptera: Culicidae) in Western Kenya Highlands. J. Med. Entomol. 42, 974-980.

Afrane, Y. A., Zhou, G., Lawson, B. W., Githeko, A. K., and Yan, G. (2006). Effects of microclimatic changes caused by deforestation on the survivorship and reproductive fitness of Anopheles gambiae in Western Kenya highlands. Am. J. Trop. Med. Hyg. 74, 772-778.

Balls, M. J., Bødker, R., Thomas, C. J., Kisinza, W., Msangeni, H. A., and Lindsay, S. W. (2004). Effect of topography on the risk of malaria infection in the Usambara Mountains, Tanzania. Trans. R. Soc. Trop. Med. Hyg. 98, 400-408.

Bødker, R., Kisinza, W., Malima, H., and Lindsay, S. (2000). Resurgence of malaria in the Usambara mountains, Tanzania, an epidemic of drug-resistant parasites. Global Change Hum. Health 1, 134-154.

Bontemps, S., Defourny, P., Van Bogaert, E., Arino, O., Kalogirou, V., and Ramos Perez, J. (2011). GlobCover2009: Products Description and Validation Report. European Space Agency and Université catholique Louvain, Brussels, Belgium.

Bradley, R. S., Vuille, M., Diaz, H. F., and Vergara, W. (2006). Threats to water supplies in the Tropical Andes. Science 312, 1755-1756.

Brinkmann, U. W. (1994). Economic development and tropical disease. Ann. N. Y. Acad. Sci. 740, 303-311.

Bromley, R. (1981). The colonization of humid tropical areas in Ecuador. Singap. J. Trop. Geogr. 2, 15-26.

Caldas de Castro, M., Monte-Mór, R. L., Sawyer, D. O., and Singer, B. H. (2006). Malaria risk on the Amazon frontier. Proc. Natl. Acad. Sci. U.S.A. 103, 2452-2457.

CANOCO. (2002). CANOCO for Windows 4.5. Wageningen: Plant Research International.

Chhabra, A., Geist, H., Houghton, R. A., Haberl, H., Braimoh, A. K., Vlek, P. L. G., Patz, J., Xu, J., Ramankutty, N., Coomes, O., and Lambdin, E. F. (2006). "Multiple impacts of landuse/cover change," in Land-use and Land-cover Change: Local Processes and Global Impacts, eds F. Lambin and H. J. Geist (Berlin: Springer Publishers), 71-87. de Koning, G. H. J., Veldkamp, A., and Fresco, L. O. (1998). Land use in Ecuador: a statistical analysis at different aggregation levels. Agric. Ecosyst. Environ. 70, 231-247.

de Oliveira, E., Soares de Santos, E., Zeilhofer, P., Souza-Santos, R., and Atanaka-Santos, M. (2011). Spatial patterns of malaria in a land reform colonization project, Juruena municipality, Mato Grosso, Brazil. Malar. J. 10, 177.

de Zulueta, J., Kafuko, G. W., McCrae, A. W. R., Cullen, J. R., Pedersen, C. K., and Wasswa, D. F. B. (1964). A malaria eradication experiment in the highlands of Kigezi (Uganda). East Afr. Med. J. 41, 102-120.

ESRI. (2008). ArcGIS version 9.2., Redlands, CA: Environmental Systems Research Institute.

Gorham, J. R., Stojanovich, C. J., and Scott, H. G. (1973). Illustrated key to the Anopheline mosquitoes of western South America. Mosq. Syst. 5, 97-155.

Grieco, J. P., Johnson, S., Achee, N. L., Masuoka, P., Pope, K., Rejmánková, E., Vanzie, E., Andre, R., and Roberts, D. (2006). Distribution of Anopheles albimanus, Anopheles vestitipennis, and Anopheles crucians associated with land use in northern Belize. $J$. Med. Entomol. 43, 614-622.

Guerra, C. A., Snow, R. W., and Hay, S. I. (2006). A global assessment of closed forests, deforestation and malaria risk. Ann. Trop. Med. Parasitol. 100, 189-204.

Hanson, H., and Montalvan, J. A. (1938). El Paludismo en Balzapamba. Quito: Panamerican Sanitation Office and Director General of the Sanitation of the Republic.

Hay, S. I., Simba, M., Busolo, M., Noor, A. M., Guyatt, H. L., Ochola, S. A., and Snow, R. W. (2002). Defining and detecting malaria epidemics in the highlands of Western Kenya. Emerg. Infect. Dis. 8, 555-562.

Hiraoka, M., and Yamamoto, S. (1980). Agricultural development in the upper Amazon of Ecuador. Geogr. Rev. 70, 423-445.

Levi Castillo, R. (1945). Anopheles pseudopunctipennis in the Los Chillos valley of Ecuador. J. Econ. Entomol. 38, 385-388.

Levi Castillo, R. (1947). Estudios sobre el paludismo en los valles Andinos de Sudamerica. Rev. Med. Cordoba 25, 343-356.

Minakawa, N., Munga, S., Atlieli, F., Mushinzimana, E., Zhou, G., Githeko, A. K., and Yan, G. (2005). Spatial distribution of anopheline larval habitats in western Kenyan highlands: effects of land cover types and topography. Am. J. Trop. Med. Hyg. 73, 157-165.

Moran, P. A. P. (1950). Notes on continuous stochastic phenomena. Biometrika 37, 17-33.

Munga, S., Yakob, L., Mushinzimana, E., Zhou, G., Ouna, T., Minakawa, N., Githeko, A., and Yan, G. (2009). Land use and land cover changes and spatiotemporal dynamics of anopheline larval habitats during a four-year period in a highland community of Africa. Am. J. Trop. Med. Hyg. 81, 1079-1084.

Oladepo, O., Tona, G. O., Oshiname, F. O., and Titiloye, M. A. (2010). Malaria knowledge and agricultural practices that promote mosquito breeding in two rural farming communities in Oyo State, Nigeria. Malar. J. 9, 91.

Paaijmans, K. P., Imbahale, S. S., Thomas, M. B., and Takken, W. (2010). Relevant microclimate for determining the development rate of malaria mosquitoes and possible implications of climate change. Malar. J. 9, 196.

Pan, W. K.-Y., Erlien, C., and Bilsborrow, R. E. (2010). Morbidity and mortality disparities among colonist and indigenous populations in the Ecuadorian Amazon. Soc. Sci. Med. 70, 401-411.

Pattanayak, S., Dickinson, K., Corey, C. Murray, B., Sills, E., and Kramer, R. (2006). Deforestation, malaria, and poverty: a call for transdisciplinary research to support the design of cross-sectoral policies. Sustain. Sci. Pract. Policy 2, 45-56.

Patz, J. A., Daszak, P., Tabor, G. M. Aguirre, A. A., Pearl, M., Epstein, J., Wolfe, N. D., Kilpatrick, A. M., Foufopoulos, J., Molyneux, D., Bradley, D. J., and Members of the Working Group on Land Use Change and Disease Emergence. (2004). Unhealthy landscapes: policy recommendations on land use change and infectious disease emergence (Meeting Report). Environ. Health Perspect. 112, 1092-1095.

Pinault, L. L., and Hunter, F. F. (2011a). New highland distribution records of multiple Anopheles species in the Ecuadorian Andes. Malar. J. 10, 236.

Pinault, L. L., and Hunter, F. F. (2011b). Malaria knowledge, concern, land management, and protection practices among land owners and/or managers in lowland versus highland Ecuador. Malaria Res. Treat. Article ID: 765125, $1-12$.
Pinault, L. L., and Hunter, F. F. (2012) Characterization of larval habitats of Anopheles albimanus, Anopheles pseudopunctipennis, Anopheles punctimacula and Anopheles oswaldoi s.l. populations in lowland and highland Ecuador. J. Vector Ecol. (in press).

Pinheiro, F. P., Bensabathm, G., Rosa, A. P. A. T., Lainson, R., Shaw, J. J., Ward, R., Fraiha, H., Moraes, M. A. P., Gueros, Z. M., Lins, Z. C., and Mendes, R. (1977). Public health hazards among workers along the trans-Amazon highway. J. Occup. Med. 19, 490-497.

Póvoa, M. M., Conn, J. E., Schlichting, C. D., Amaral, J. C. O. F., Segura, M. N. O., Da Silva, A. N. M., Dos Santos, C. C. B., Lacerda, R. N. L., De Souza, R. T. L., Galiza, D., Santa Rosa, E. P., and Wirtz, R. A. (2003). Malaria vectors, epidemiology, and the re-emergence of Anopheles darlingi in Belém, Pará, Brazil. J. Med. Entomol. 40, 379-386.

Reiter, P. (2001). Climate change and mosquito-borne disease. Environ. Health Perspect. 109, 141-161.

Rejmankova, E., Savage, H. M., Rejmanek, M., Arredondo-Jimenez, J. I., and Roberts, D. R. (1991). Multivariate analysis of relationships between habitats, environmental factors and occurrence of anopheline mosquito larvae Anopheles albimanus and A. pseudopunctipennis in Southern Chiapas, Mexico. J. Appl. Ecol. 28, 827-841.

Rutar, T., Baldomar Salguiero, E. J., and Maguire, J. H. (2004). Introduced Plasmodium vivax malaria in a Bolivian community at an altitude of 2,400 meters. Am. J. Trop. Med. 70, 15-19.

Sarmiento, F. O. (2002). Anthropogenic change in the landscapes of highland Ecuador. Geogr. Rev. 92, 213-234.

Shanks, G. D., Biomndo, K., Hay, S. I., and Snow, R. W. (2000). Changing patterns of clinical malaria since 1965 among a tea estate population located in the Kenyan highlands. Trans. R. Soc. Trop. Med. Hyg. 94, 253-255.

SNEM. (1995-2009). Information of Malaria Morbidity Zones at the National Level. Guayaquil: Servicio Nacional de Control de Malaria, Government of Ecuador.

Tadei, W. P., Dutary Thatcher, D., Santos, J. M. M., Scarpassa, V. M., Brandao Rodrigues, I., and Silva Rafael, M. (1998). Ecologic observations on Anopheline vectors of malaria in the Brazilian Amazon. Am. J. Trop. Med. Hyg. 59, 325-335. 
Vergara, W., Deeb, A. M., Valencia, A. M., Bradley, R. S., Francou, B., Zarzar, A., Grünwaldt, A., and Haeussling, S. M. (2007). Economic impacts of rapid glacier retreat in the Andes. Eos (Washington DC) 88, 261-264.

Walsh, J. F., Molyneux, D. H., and Birley, M. H. (1993). Deforestation: effects on vector-borne disease. Parasitology 106, S55-S75.

Whitlock, M. C., and Schluter, D. (2009). The Analysis of Biological Data. Colorado: Roberts and Company Publishers.

Wood, H. A. (1972). Spontaneous agricultural colonization in
Ecuador. Ann. Assoc. Am. Geogr. 62, 599-617.

Yasuoka, J., and Levins, R. (2007). Impact of deforestation and agricultural development on anopheline ecology and malaria epidemiology. Am. J. Trop. Med. Hyg. 76, 450-460.

Yomiko Vittor, A., Gilman, R. H., Tielsch, J., Glass, G., Shields, T., Sánchez Lozano, W., Pinedo-Cancino, V., and Patz, J. A. (2006). The effect of deforestation on the humanbiting rate of Anopheles darlingi, the primary vector of falciparum malaria in the Peruvian
Amazon. Am. J. Trop. Med. Hyg. 74, 3-11.

Conflict of Interest Statement: The authors declare that the research was conducted in the absence of any commercial or financial relationships that could be construed as a potential conflict of interest.

Received: 01 December 2011; accepted: 29 February 2012; published online: 20 March 2012.

Citation: Pinault $L L$ and Hunter FF (2012) Larval habitat associations with human land uses, roads, rivers, and land cover for Anopheles albimanus, A. pseudopunctipennis, and A. punctimacula (Diptera: Culicidae) in coastal and highland Ecuador. Front. Physio. 3:59. doi: 10.3389/fphys.2012.00059

This article was submitted to Frontiers in Systems Biology, a specialty of Frontiers in Physiology.

Copyright (๑) 2012 Pinault and Hunter. This is an open-access article distributed under the terms of the Creative Commons Attribution Non Commercial License, which permits non-commercial use, distribution, and reproduction in other forums, provided the original authors and source are credited. 